\title{
ASPECTOS MORFOLÓGICOS E ULTRAESTRUTURAIS DO ESPERMATOZÓIDE DE Curimata inornata VARI, 1989 (PISCES,TELEOSTEI) DO RIO AMAZONAS.
}

\author{
Edilson MATOS 1 , Patricia MATOS ${ }^{2}$, Márcia N. S. SANTOS ${ }^{2}$, Carlos AZEVEDO ${ }^{3}$
}

RESUMO - Estão descritos aspectos morfológicos e ultraestruturais do espermatozóide de Curimata inornata Vari, 1989 (Pisces, Teleostei) observados com microsopia óptica e microscopia eletronica de transmissão. O espermatozóide é constituído de cabeça, contendo um núcleo ovoide com cromatina granular densa, uma peça intermediária curta e uma cauda com a constituição axonëmica clássica de microtúbulos de $9 \mathrm{p}+2$.

Palavras chave: Ultraestrutura, espermatozóide, peixe amazonico, teleósteo.

Morphological and Uitrastructural Aspects of the Spermatozoon of Curimata inornata Vari, 1989 (Pisces, Teleostei) from the Amazon River.

ABSTRACT - Morphological and ultrastructural aspects of the spermatozoon of Curimata inornata Vari, 1989 (Pisces, Teleostei) is described by light and transmission electron microscopy. the spermatozoon head contains a nucleus ovoid-shaped, with granular chomatin electron dense, a short middle piece and a tail, with the classic $9+2$ axoneme.

KEY WORDS: Ultrastructure, Spermatozoon, Amazonian Fish, Teleost.

\section{INTRODUÇÃO}

A estrutura de espermatozóides de várias classes de vertebrados tem sido estudada, sendo a maior diversidade encontrada em peixes, embora menor nestes animais quando comparada com os invertebrados (Baccetti, 1970; Mattei et al., 1989). A cabeça do espermatozóide pode apresentar diversas formas, tais como, ligeiramente alongada, achatada ou ovóide (Matos e Azevedo, 1989; Lahnsteiner and Patzner, 1990). Espermatozóides com ou sem acrosoma (Baccetti, 1970), com um ou dois flagelos (Mattei, 1988; Matos e Azevedo, 1989; Mattei et al., 1989; Jamieson, 1991).

Observações nos testículos de peixes tem revelado que a maioria dos teleósteos apresenta a gonada masculina par, com ductos espermáticos separados (Barlow et al., 1968). Conforme a morfologia apresentada, o espermatozóide pode ser considerado como do tipo clássico, primitivo ou modificado. No presente estudo observamos os aspectos morfológicos e ultraestruturais do espermatozóide de Curimata inornata, com a finalidade de determinar o tipo em que se enquadra, após observações do seu ciclo espermatogênico.

\section{MATERIAL E MÉTODOS}

Espécimes de coaca Curimata inornata Vari,1989 foram coletados nos braços do rio Peixe Boi ( $01^{\circ} 11^{\prime} 30^{\prime \prime} \mathrm{S} 47^{\circ}$ $18^{\prime} 54^{\prime \prime}$ W) durante o período em que se processa o amadurecimento gonadal. Fragmentos dos testículos foram fixados em glutaraldeido a $3 \%$ tamponado com

Faculdade de Ciências Agrárias do Pará, Departamento de Biologia Animal, Histologia e Embriologia, Av. Tancredo Neves S/N, 66.077-530, Belém - Pará,

2 Universidade Federal do Pará, Departamento de Histologia e Embriologia, 66.059-900, Belém - Pará.

3 Universidade do Porto, ICBAS - Departamento de Biologia Celular, 4.050, Porto - Portugal. 
cacodilato de sódio $0,1 \mathrm{M} \mathrm{pH} \mathrm{7,2} \mathrm{a} 4^{\circ} \mathrm{C}$ durante 2 horas. Após lavagem no mesmo tampão, durante $2-3$ horas a $4^{\circ} \mathrm{C}$, os fragmentos foram pós-fixados em tetróxido de ósmio a $2 \%$ tamponado também em cacodilato de sódio a $4^{\circ} \mathrm{C}$ durante 2 horas. O material foi desidratado em série crescente de álcool etílico, seguido de 3 trocas de óxido de propileno. A inclusão foi feita em Epon, os cortes semifinos e ultrafinos em ultramicrótomo com faca de diamante, e a dupla contrastação com solução aquosa saturada de acetato de uranila e citrato de clumbo (Azevedo et al., 1985). Os cortes foram examinados e fotografados ao microscópio eletrônico de transmissão JEOL 100 CXII operando a 60 $\mathrm{Kv}$. Alguns fragmentos de testiculo foram pressionados entre laminas de vidro com glutaraldeído a 3\% tamponado com cacodilato de sódio $0,1 \mathrm{M} \mathrm{pH} 7,2$, e fixados nesta solução a $4^{\circ} \mathrm{C}$ durante 2 horas e após mantidos em tampão cacodilato de sódio, montados entre lamina / laminula e observados em microscopio óptico equipado com contraste de interferência de fase Nomarski (DIC) .

\section{RESULTADOS}

O espermatozóide de coaca Curimata inornata Vari, 1989 apresenta uma organização típica do tipo primitivo, relativamente simples, dividido em cabeça sem acrosoma, peça intermediảria mal definida e cauda (Fig. 1).

Durante o processo de maturação gonadal observa-se que o testículo apresenta túbulos seminíferos contendo cistos espermáticos delimitados por camada única de células, correspondentes às de Sertoli. Observa- se que as células germinativas desenvolvem sincronicamente dentro dos cistos os estágios da espermatogênese, os quais podem ser facilmente identificados (Figs. 2 e 3 ). $\mathrm{O}$ núcleo apresenta-se ligeiramente ovóide coberto por um envoltório nuclear, com contornos levemente irregulares, mitocondrias e uma bainha citoplasmática que vai se afinando em direção a cauda (Fig. 4). A fossa nuclear abriga o complexo centriolar, e o centriolo distal forma o corpo basal do axonema. $\mathrm{O}$ colar mitocondrial envolve o flagelo, ficando completamente separado dele pela região citoplasmática.

O axonema é coberto pela membrana plasmática, apresentando flagelo do tipo $9 p+2$ (Fig. 5)

\section{DISCUSSÃO}

O estudo de espermatozóides de peixes teleósteos em microscopia eletronica de transmissão tem demonstrado características morfologicas importantes, podendo inclusive contribuir para a identificação de diferentes espécies (Mattei, 1991; Gwo and Arnold, 1992; Gwo et al., 1992), assim como também pode ser usado para propósitos taxonômicos (Jamieson, 1991; Mattei, 1991). A descrição da ultraestrutura dos espermatozoides tem provado ser de valor filogenético em muitos grupos de animais (Healy, 1987; Jamieson, 1989; Jamieson and Rouse, 1989). Aspetos ultraestruturais dos espermatozóides de peixes mostram pequenas diferenças entre estes, especialmente no que diz respeito ao núcleo e fossa nuclear, número de mitocondrias (Gwo et al.,1993), assim como a região do corpo basal de espermatozóides de vertebrados 

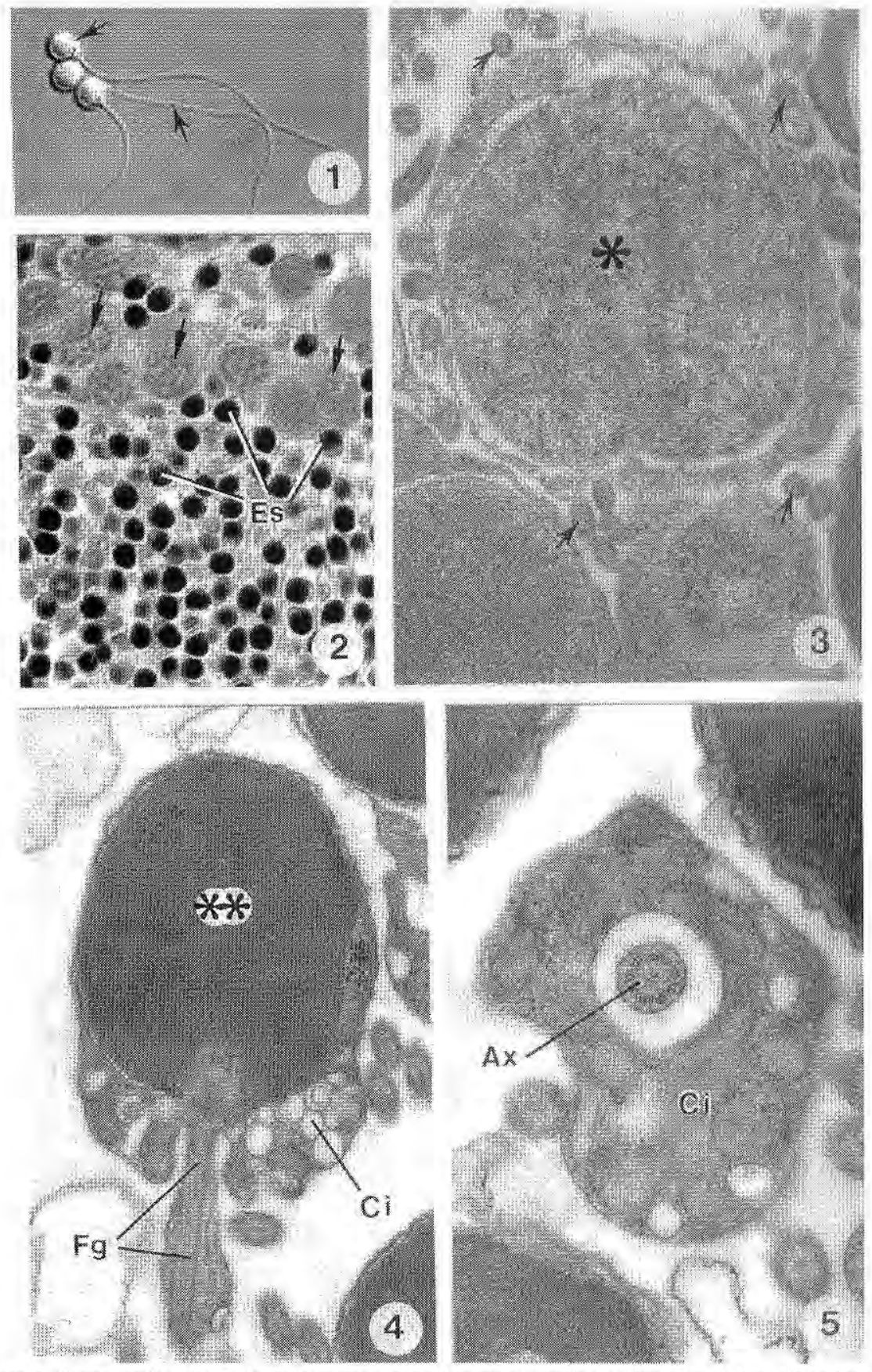

Figura 1. Espermtozóides de Curimata inotnuta observados em microseopia de contraste de fase diferencial (DIC) (Nomarski), X 1525.

Figura 2. Corte semifíno de gonada de Curimuta inomuta mostrando espermatocitos (setas) e espermatozoides (Es). X 1400. Figura 3. Corte ultrafino de espermátide $\left({ }^{*}\right)$ e cortes transversais de flagelos (setas). X 14000.

Figura 4. Corte ultrafino de espermatozóide (**) con núcleo denso, citoplasma basal (Ci) e o flagelo (Fg). X 15200.

Figura 5. Corte transversal de flagelo mostrando o axonema $(\Lambda \mathrm{x})$. A sua volta observa-se o citoplasma (Ci). X 32000 . 
(Anderson, 1972; Wheatley, 1982). As projeções laterais citoplasmáticas são raramente descritas em espermatozóides de peixes teleósteos, assim como estruturas citoplasmáticas que possam estar envolvendo o complexo centriolar, e de natureza desconhecida, ou também quanto ao flagelo, onde todas estas estruturas são pouco mencionados na morfologia dos espermatozóides de peixes (Grier, 1973, 1976; Lahnsteiner et al.,1991). Estes fatos justificam a investigação ultraestrutural em várias espécies, onde diferenças morfológicas, tem importante significado funcional e evolutivo (Gwo, 1995). Os aspectos morfológicos e ultraestruturais do espermatozóide de Curimata inornata caracterizam-no como do tipo primitivo após observações do seu ciclo espermatogênico ( Billard, 1983; Lou \& Takahashi, 1989; Matos et al., 1993)

\section{AGRADECIMENTOS}

Ao Dr Heraldo Britski do Museu de Zoologia da USP pela identificação da espécie. Ao Sr João Carvalheiro pelo trabalho iconográfico. Trabalho parcialmente subsidiado pela JNICT e IMAR (Portugal), FCAP e UFPa.

\section{Bibliografia citada}

Anderson, R.G.W. 1972. The three-dimensional structure of the basal body from the rhesus monkey oviduct. J. Cell, Biol., 54: 246- 265.

Azevedo, C.; Lobo-da-Cunha, A ;) Oliveira,E. 1985. Ultrastructure of the spermatozoon in Gibulla umbilicalis (Gastropoda, Prosobranchia) with special reference to acrosomal formation. $J$. Submicrosc. Cytol, 17: 609-614.

Baccetti, B. 1970. Comparative Spermatology. Academic Press, New York, New York.

Barlow, G.F; Liem, K.F; Wickler, W. 1968. Badidae, a new fish family : behavioural, os- teological and development evidence. Zoology (London) 156:415-447.

Billard, R. 1983. Ultrastrucuture of trout spermatozoa : changes after dilution and deep freezing. Cell. Tisue Res., 228: 205-218.

Grier, H.J. 1973. Ultrastructure of the testis in the teleost Poecilia latipinna spermiogenesis with reference to the intercentriolar lamellated body. J. Ultrastruct. Res., 45: 82-92,

Grier, H.J. 1976. Sperm development in teleost Oryzias latipes. Cell, Tissue. Res., 168: 419-431.

Gwo, J.C. 1995. Spermatozoan ultrastructure of the teleost fish Acanthopagrus latus (Perciformes: Sparidae) with special reference to the basal body. J. Submicrosc. Cytol, Pathol, 27: 391-396.

Gwo, J.C.; Arnold, C.R. 1992. Cryopreservation of Atlantic croaker spermtozoa : evaluation of morphological changes, J. Exp. Zool, 264: 444-453,

Gwo, J.C.; Gwo, H.H.; Chang, S.L. 1992. The spermatozoon of the Japanese eel, Anguilla japonica (Teleostei, Anguilliformes, Anguillidae), J.Submicrosc. Cytol. Pathol., 24; 571-574.

Gwo, J.C; Gwo, H.H.; Chang, S.L. 1993. The ultrastructure of Acanthopagrus schlegeli spermatozoon.J.Morphol., 216: 29-33.

Healy, J. M. 1987. Spermatozoon ultrastructure and its bearing on gastropod classification and evolution. Anat.Zool., 24: 108-113.

Jamieson, B.G.M. 1989. A comparison of the spermatozoa of Oratosquilla stenphensoni and Squilla mantis (Crustacea,Stomatopoda) with comments on the phylogeny of the Malacostraca. Zool.Scr., 18: 509-517.

Jamieson, B.G.M. 1991. Fish evolution and Systematics : evidence from spermatozoa. Cambridge University Press, pp 319, Cambridge.

Jamieson, B.G.M.; Rouse, G.W. 1989. The spermatozoa of the polychaeta (Annelida): An ultrastructural review. Biol.Ver, 64: 93-157.

Lahnsteiner, F; Patzner, R. A. 1990. Spermiogenesis and structure of mature spermatozoa in blenniid fishes (Pisces, Blenniidae). J.Submicrosc.Cytol.Pathol., 22: 565-576. 
Lahnsteiner, F.; Patzner, R.A.; Weismann, T. 1991. The fine structure of spermatozoa of the grayling, Thymallus thymallus (Pisces, Teleostei). J. Submicrosc. Cytol. Pathol., 23: 373-377.

Lou, Y.H.; Takahashi, H. 1989. Spermiogenesis in the Nile Tilapia Oreochromis niloticus with notes a unique pattern of nuclear chromatin condensation. J.Morph., 200: 321-330.

Matos, E.; Azevedo, C. 1989. Ultraestrutura da espermatogenese de Lepidosiren paradoxa (Pisces,Dipnoi) na Amazonia. Rev. bras.Cièn.morfol. 6: 67-71.

Matos, E.; Matos, P.; Oliveira, E.; Azevedo, C. 1993. Ultraestrutura da espermatogênese do tamoatá Hoplosternum littorale (Hancock)(Teleostei,Callichthyidae) do rio Amazonas. Revta.bras.Zool., 10: 215-218.
Mattei, X. 1988. The flagellar apparatus of spermatozoa in fish. Ultrastructure and evolution. Biology of the Cell., 63: 151-158.

Mattei, X.; Thiam, D.; Thaw, O.T. 1989. Le spermatozoide de Ophidion sp. (Poisson,Téléostéen): Particularities ultrastructurales du flagelle. J. Ultrastr. Molec. Struct.Res., 102: 162-169.

Mattei, X. 1991. Spermatozoon ultrastructure and its systematic implications in fishes. Can. J. Zool., 69: 3038-3055.

Wheatley, D.N. 1982. The centriole : A central enigma of cell biology. Elsevier. Amsterdam. 